\title{
CEMENTLESS TOTAL REPLACEMENT FOR OLD TUBERCULOSIS OF THE HIP
}

\author{
A. ESKOlA, S. SANTAVIRTA, Y. T. KONTTINEN, K. TALlROTH, V. HOIKKA, S. T. LiNDHOLM \\ From Helsinki University Central Hospital
}

\begin{abstract}
We report the results of cementless total joint replacement in 18 patients with old tuberculosis of the hip, performed, on average, 34 years after the onset of infection. Mean follow-up was 3.5 years. Only seven of the patients had antituberculous drugs during or after the operation.

Using the Mayo hip score, 15 patients had excellent or good results and two had a fair rating. One patient had the prosthesis removed more than one year postoperatively for late haematogenous staphylococcal infection and had a poor rating. All the patients had relief of hip-related pain. Despite the absence of any reactivation of tuberculosis in our series, we recommend the use of specific prophylaxis.
\end{abstract}

Few reports have been published on total hip replacement in the treatment of old tuberculosis. Many experts advise against this mode of treatment, because of the increased risk of postoperative infection due to bacteraemic seeding or local recurrence (McCullough 1977; Hardinge, Cleary and Charnley 1979; Johnson, Barnes and Owen 1979). However, severe destruction and deformity of the hip often produces pain, and natural ankylosis or surgical fusion may cause low back pain and discomfort in the knee. The Girdlestone procedure is not without complications, and many patients are unwilling to accept the consequent leg shortening.

Since 1982, we have used cementless total joint replacement to treat patients with old tuberculosis of the hip. We have analysed this experience and report the outcome.

\section{PATIENTS AND METHODS}

From 1982 to 1985 , at the Orthopaedic Hospital of the Invalid Foundation in Helsinki, 18 patients had a cementless hip replacement for old tuberculosis. All patients had a well-documented history with positive cultures as well as full clinical and radiographic followup.

A. Eskola, MD, Research Fellow

S. Santavirta, MD, PhD, Consultant Surgeon

K. Tallroth, MD, PhD, Senior Radiologist

V. Hoikka, MD, PhD, Research Fellow

S. T. Lindholm, MD, PhD, Senior Physician

The Orthopaedic Hospital of the Invalid Foundation, Tenholantie 10, SF-00280 Helsinki, Finland.

Y. T. Konttinen, MD, PhD, Assistant Professor

Fourth Department of Medicine, Division of Rheumatic Diseases, Unioninkatu 38, 00170 Helsinki, Finland.

Correspondence should be sent to Dr A. Eskola.

(C) 1988 British Editorial Society of Bone and Joint Surgery $0301-620 X / 88 / 4110 \$ 2.00$

J Bone Joint Surg [Br] $1988 ; 70-\mathrm{B}: 603-6$.
There were 14 women and four men, with 11 right hips and seven left hips involved. Primary infection had usually been in childhood at an average age of 12 years, but two patients were over 20 years at the onset of the infection (range 3 to 47 years). The mean age at the time of operation was 46 years (range 36 to 60 ), so the arthroplasty was performed on average 34 years after the primary infection.

Surgical fusion of a tuberculous hip had been successfully performed on one patient, and another hip had fused spontaneously. In these two cases hip replacement was indicated mainly for low back pain caused by the stiff hip. The other 16 patients had pain from severe destruction and deformity of the joint and in these the average range of extension-flexion was $40^{\circ}$ (range 0 to $90^{\circ}$ ). Three patients had flexion deformities of $10^{\circ}$ to $20^{\circ}$. The average leg shortening in 13 patients was $26 \mathrm{~mm}$ (range 10 to $50 \mathrm{~mm}$ ) as assessed by erect radiographs, and seven had severe quadriceps atrophy. All the patients had a normal ESR.

None of the patients had received long-term antibiotics before operation, and only seven were given prophylactic treatment with $600 \mathrm{mg}$ rifampicin and $300 \mathrm{mg}$ isoniazid daily, supplemented with pyridoxine. This was started during the operation and continued for six to 12 months. Thus 11 of the patients did not have antituberculous treatment.

All the patients had $2000 \mathrm{mg}$ flucloxacillin daily for five days, which is our routine for the revision of total hip arthroplasties. During the operation, routine bacterial and tuberculosis cultures and specimens for histopathology were taken; all the results were negative.

An uncemented Lord prosthesis was used in all cases, and patients were encouraged to walk with crutches from the first postoperative day. Full weightbearing without crutches was allowed three months after the operation. 
Figure 1 - The ankylosed hip joint of a 48year-old woman, who had suffered tuberculous infection at six years of age. Figure 2 Three-and-a-half years after cementless hip replacement the clinical result was good and the radiograph shows good incorporation.

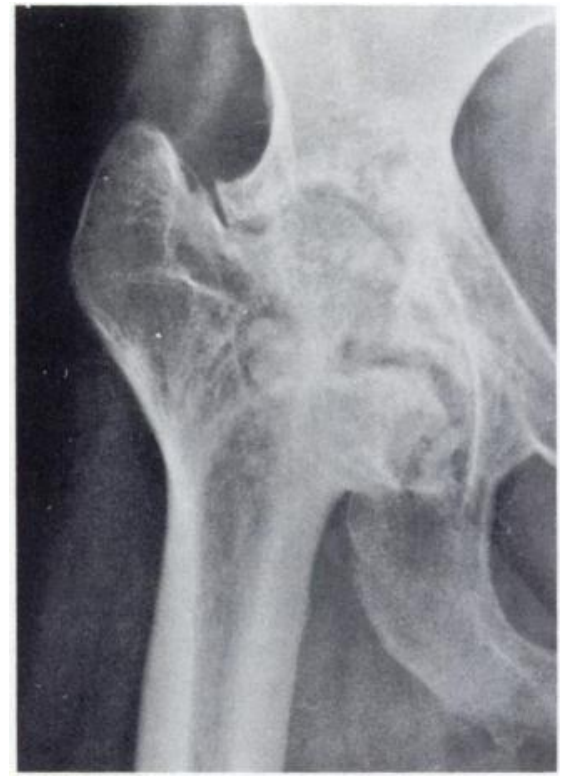

Fig. 1

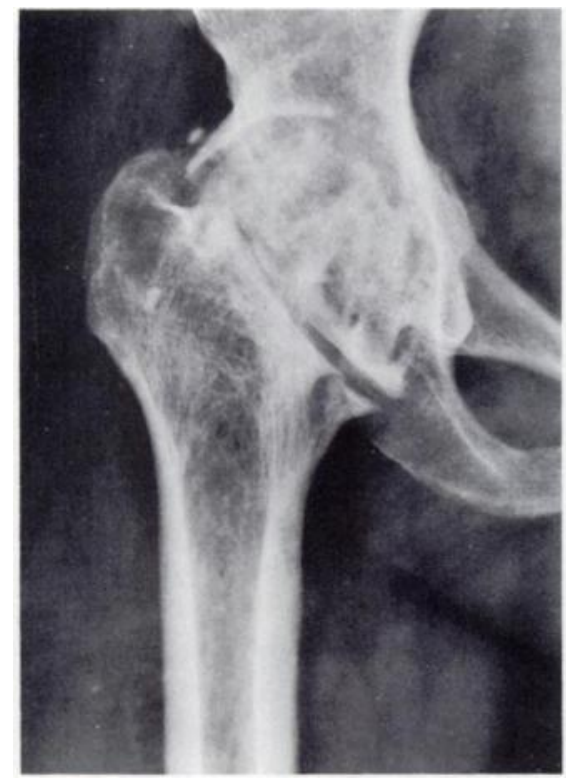

Fig. 3

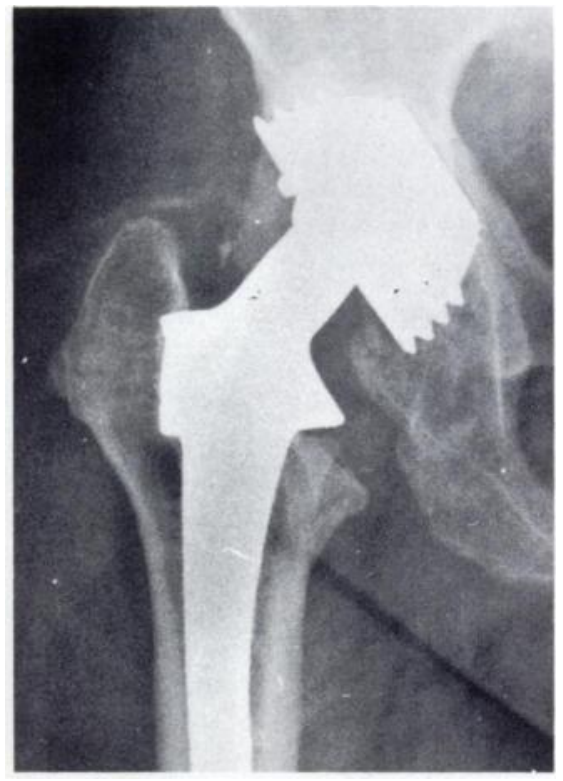

Fig. 4

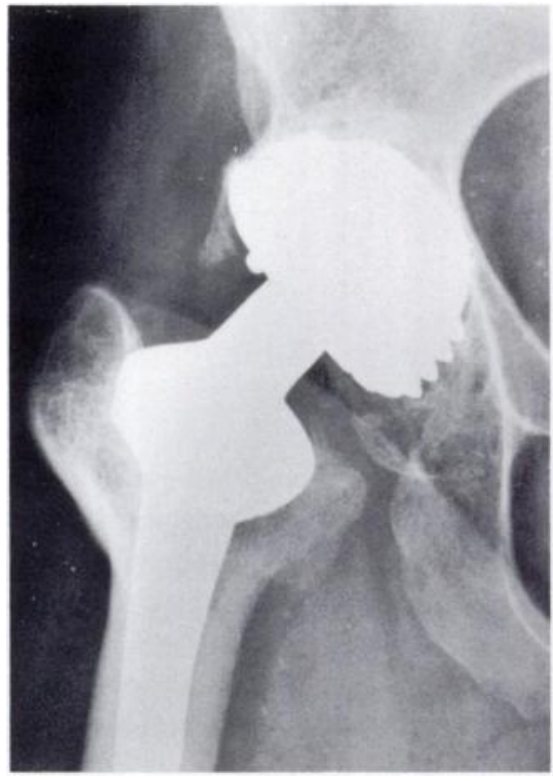

Fig. 2

Figure 3 - Radiograph of the painful hip of a 46-year-old woman who had had tuberculous infection at 13 years of age. Flexion was only $30^{\circ}$. Figure 4 - Four years after total replacement the patient has a normal gait and the radiograph shows no radiolucency around the prosthesis.

The average duration of follow-up was 3.5 years (range 2 to 5.5 years). Clinical and radiographic examinations were performed (Figs 1 to 4 ) and ESR and $\mathrm{C}$-reactive protein levels were recorded.

\section{RESULTS}

Complications. One patient had a superficial wound infection which was successfully treated with short-term systemic antibiotics. One patient had a dislocation of the prosthesis on the second postoperative day, secondary to excess anteversion of the cup. This was corrected at an early re-operation with no further complications.

Twelve months after operation another patient developed a staphylococcal infection requiring removal of the prosthesis. This patient had been treated with flucloxacillin for seven months after operation for chronic sinusitis, and it is believed that the hip infection was due to metastatic haematogenous spread from the sinus. There were no other complications during followup.

Assessment. At follow-up the Mayo hip score (Kavanagh and Fitzgerald 1985) was calculated for all patients. In this scoring system, clinical history and evaluation account for 80 of the 100 points; there are 40 points for pain, 20 for hip function (based on the distance walked and the use of external aids), 20 points for hip mobility and muscle power and 20 points for radiographic appearance.

The mean clinical score for all 18 patients before 
operation was 46 out of 80 points, and at follow-up 68 points. Excluding the patient with removal of the prosthesis for infection gave a mean score of 75.3. The total mean score, including the radiographic evaluation, was 89.9 out of 100 points, and excluding the patient whose prosthesis had been removed, it was 94.1 points (Table I). Good or excellent results ( 80 to 100 points) were seen in 15 patients, two patients had fair rating ( 70 to 79 points), and only the patient whose prosthesis was removed had a poor result. All the patients reported a reduction in hip-related pain, including the back pain in the patients with previously fused hips.

The range of movement at the hip had increased in all cases, giving an average flexion of $86.1^{\circ}$, though two patients had $10^{\circ}$ loss of extension. While 13 patients had an average leg shortening of $26 \mathrm{~mm}$ before operation, only seven patients had an average of $13 \mathrm{~mm}$ after operation (Table I). The seven patients with severe quadriceps atrophy showed no improvement, despite physiotherapy, and the other patients also showed relatively little improvement in function of this muscle.

None of the patients showed an elevated ESR or
C-reactive protein at follow-up, and there were no radiographic signs of loosening of the prostheses. In one case, Grade II ectopic ossification was recorded.

\section{DISCUSSION}

In Finland, as in most other industrialised countries, tuberculous arthritis of the hip has become rare. However, throughout the rest of the world, this disease still cripples a large number of patients and there is need for an effective and acceptable treatment. Older procedures, such as Girdlestone excision, hip fusion and interposition arthroplasty have given good results (Katayama, Itami and Marumo 1962; Vishwakarma and Khare 1986), but these are inferior to the outcome of modern total replacement operations.

There are only a few reports of patients with old tuberculosis of the hip treated by total arthroplasty (Jupiter et al. 1981; Kim et al. 1986; Laforgia, Murphy and Redfern 1988). This management of tuberculous hips has been criticised because of the danger of reactivation of cured or quiescent disease (McCullough

Table I. Results in 18 patients at a mean of 3.5 years after cementless total replacement for old tuberculosis of the hip

\begin{tabular}{|c|c|c|c|c|c|c|c|c|c|}
\hline \multirow[b]{2}{*}{$\begin{array}{l}\text { Case } \\
\text { number }\end{array}$} & \multirow[b]{2}{*}{$\begin{array}{l}\text { Age in } \\
\text { years }\end{array}$} & \multirow[b]{2}{*}{ Sex } & \multirow[b]{2}{*}{$\begin{array}{l}\text { Flexion in } \\
\text { degreest }\end{array}$} & \multirow[b]{2}{*}{$\begin{array}{l}\text { Leg } \\
\text { shortening } \\
(\mathrm{cm})\end{array}$} & \multicolumn{5}{|c|}{ Mayo score (see text) } \\
\hline & & & & & Pain & Function & $\begin{array}{l}\text { Range of } \\
\text { movement and } \\
\text { muscle function }\end{array}$ & Radiograph & Total \\
\hline 1 & 47 & $\mathbf{F}$ & 80 & 0 & 35 & 12 & 9 & 20 & 76 \\
\hline 2 & 53 & $\mathbf{F}$ & 120 & 0 & 40 & 20 & 20 & 20 & 100 \\
\hline 3 & 38 & $\mathbf{F}$ & 90 & 0 & 40 & 20 & 20 & 20 & 100 \\
\hline 4 & 55 & $\mathbf{F}$ & 90 & 0 & 35 & 20 & 18 & 20 & 93 \\
\hline 5 & 47 & $\mathbf{M}$ & 10 to 95 & 1.0 & 40 & 20 & 18 & 20 & 98 \\
\hline 6 & 48 & $\mathbf{F}$ & 70 & 1.0 & 40 & 20 & 20 & 20 & 100 \\
\hline 7 & 36 & $\mathbf{M}$ & 120 & 0.5 & 40 & 20 & 18 & 20 & 98 \\
\hline 8 & 47 & $\mathbf{F}$ & 70 & 0 & 35 & 20 & 18 & 20 & 93 \\
\hline 9 & 59 & $\mathbf{F}$ & 80 & 0 & 35 & 15 & 11 & 20 & 81 \\
\hline 10 & 37 & $\mathbf{M}$ & 55 & 0 & 40 & 16 & 13 & 10 & 79 \\
\hline 11 & 60 & $\mathbf{F}$ & 100 & 0 & 40 & 20 & 20 & 20 & 100 \\
\hline 12 & 40 & $\mathbf{F}$ & 90 & 0 & 35 & 20 & 20 & 20 & 95 \\
\hline 13 & 39 & $\mathbf{F}$ & 90 & 2.0 & 40 & 20 & 20 & 20 & 100 \\
\hline 14 & 46 & $\mathbf{F}$ & 70 & 0 & 40 & 19 & 17 & 20 & 96 \\
\hline $15^{*}$ & 44 & $\mathbf{F}$ & 120 & $*$ & 0 & 10 & 9 & 0 & 19 \\
\hline 16 & 42 & $\mathbf{M}$ & 10 to 60 & 2.0 & 35 & 20 & 16 & 20 & 91 \\
\hline 17 & 40 & $\mathbf{F}$ & 100 & 1.0 & 40 & 20 & 20 & 20 & 100 \\
\hline 18 & 46 & $F$ & 90 & 0 & 40 & 20 & 20 & 20 & 100 \\
\hline
\end{tabular}

* Prosthesis removed for late haematogenous staphylococcal infection

† From $0^{\circ}$ unless stated 
1977; Hardinge et al. 1979; Johnson et al. 1979), and this has been reported in a few patients (Hecht et al. 1983; Delrieu et al. 1986). It is uncertain whether this is due to the local effect of trauma, to the prosthesis and the cement or to the subsequent activation of an immuneinflammatory response (Konttinen et al. 1983; Bergroth et al. 1987). It may even be due to the immunosuppressive effect of major surgery and anaesthesia. Corticosteroids or even non-steroidal anti-inflammatory drugs may have the potential to reactivate quiescent tuberculosis (Tomasson, Brennan and Bass 1984).

In our series, 11 of the 18 patients had their operation without cover by antituberculous drugs and none had any recrudescence of tuberculosis. This is interesting, but we do not recommend total hip replacement without antituberculous prophylaxis, since reactivation of tuberculosis is potentially dangerous. All our patients had had proper primary treatment with long-term antituberculous drugs, but Jupiter et al. (1981) report operations on patients who had never received modern antituberculous chemotherapy; they were treated with one contemporary drug for at least one year before their arthroplasty. Modern antituberculous therapy is indicated before the total replacement of a hip which has previously been subject to tuberculous infection.

Our results with a cementless prosthesis appear to be better than those reported in two recent series of patients with cemented prostheses (Kim et al. 1979, 1986), and are similar to those of Jupiter et al. (1981). Kim's patients were operated on 10 years after their tuberculosis was considered to be cured, while the time lapse averaged 34 years in our series and 37 years in the cases of Jupiter et al.

Our use of a cementless prosthesis could be regarded as unconventional, but almost all our revision cases, arising from over 500 primary total replacements each year, are treated by a cementless arthroplasty. Our results suggest that this type of arthroplasty is indicated in patients with an increased risk of deep infection.

Although, in the past, we did not routinely use prophylactic antituberculous drugs, we now recommend a drug regime of rifampicin and isoniazid for three weeks before operation and six to nine months after operation. This regime corresponds to that suggested by Kim et al. (1986). The reason for our changed policy is the disastrous effect of reactivation of tuberculosis. The risk of this complication appears to be small in patients such as ours, who have had thorough primary treatment, but the benefits of prophylactic cover do seem to outweigh any possible iatrogenic effects.

This study was financially supported by the Paulo Foundation and the Finska Läkaresällskapet Foundation.

No benefits in any form have been received or will be received from a commercial party related directly or indirectly to the subject of this article.

\section{REFERENCES}

Bergroth V, Konttinen YT, Nordström D, Petersson T, Tolvanen E. Lymphocyte subpopulations, activation phenotypes, and spontaneous proliferation in tuberculous pleural effusions. Chest 1987;91:338-41.

Delrieu F, Slaoui O, Evrard J, Amor B, Postel M, Kerboull M. L'infection mycobactérienne de la hanche après prothèse totale: etude de 67 cas. Rev Rheum Mal Osteoartic Imp 1986;53:113-8. (Eng. abstr.)

Hardinge K, Cleary J, Charnley J. Low-friction arthroplasty for healed septic and tuberculous arthritis. J Bone Joint Surg [Br] 1979;61-B:144-7.

Hecht RH, Meyers MH, Thornhill-Joynes M, Montgomerie JZ. Reactivation of tuberculous infection following total joint replacement: a case report. J Bone Joint Surg [Am] 1983;65:1015-6.

Johnson R, Barnes KL, Owen R. Reactivation of tuberculosis after total hip replacement. J Bone Joint Surg [Br] 1979;61-B:148-50.

Jupiter JB, Karchmer AW, Lowell JD, Harris WH. Total hip arthroplasty in the treatment of adult hips with current or quiescent sepsis. J Bone Joint Surg [Am] 1981;63-A:194-200.

Katayama R, Itami Y, Marumo E. Treatment of the hip and knee-joint tuberculosis: an attempt to retain motion. J Bone Joint Surg [Am] 1962;44-A :897-917.

Kavanagh BF, Fitzgerald RH Jr. Clinical and roentgenographic assessment of the total hip arthroplasty: a new hip score. Clin Orthop 1985;193:133-40.

Kim YY, Ko CU, Lee SW, Kwak BM. Replacement arthroplasty using the Charnley prosthesis in old tuberculosis of the hip. Int Orthop 1979;3:81-8.

Kim YY, Ahn BH, Bae DK, Ko CU, Lee JD, Kwak BM, Yoon YS. Arthroplasty using the Charnley prosthesis in old tuberculosis of the hip: clinical experience with 8-10 year follow-up evaluation. Clin Orthop 1986;211:116-21.

Konttinen YT, Bergroth V, Visa-Tolvanen K, Reitamo S, Förström L. Cellular infiltrate in situ and response kinetics of human intradermal and epicutaneous tuberculin reactions. Clin Immunol Immunopathol 1983;28:441-9.

Laforgia R, Murphy JCM, Redfern TR. Low friction arthroplasty for old quiescent infection of the hip. $J$ Bone Joint Surg $[\mathrm{Br}]$ 1988;70:373-6.

McCullough CJ. Tuberculosis as a late complication of total hip replacement. Acta Orthop Scand 1977;48:508-10.

Tomasson HO, Brennan M, Bass MJ. Tuberculosis and nonsteroidal anti-inflammatory drugs. Can Med Assoc J 1984;130:275-8.

Vishwakarma GK, Khare AK. Amniotic arthroplasty for tuberculosis of the hip: a preliminary clinical study. J Bone Joint Surg [Br] 1986;68:68-74. 